Artículos Científicos

\title{
Sinergia en la formulación de un problema de investigación.Camino a una mirada interdisciplinar
}

\author{
Sinergy in the Formulation of a Research Problem. Path to an \\ Interdisciplinary Look
}

\section{Sinergia naformulação de um problema de pesquisa. Caminho para umolhar interdisciplinar}

Vivian Aurelia Minnaard Universidad Fraternidad de Agrupaciones Santo Tomás de Aquino, Argentina minnaard@ufasta.edu.ar https://orcid.org/0000-0002-1805-5785

\section{Resumen}

La búsqueda deactividades que promuevan el trabajo colaborativo en alumnosde la cátedra de Metodología de la Investigación de la Universidad Fraternidad de Agrupaciones Santo Tomás de Aquino dela ciudad de Mar del Plata, Argentina, es un desafío permanente. Por lo que se propone como objetivo analizarel uso deestrategias y recursos seleccionados por la titular de dicho curso en las cuatro carrerasdela Facultad de Ciencias Médicaspara que los alumnosformulen un problema de investigación deforma interdisciplinariay colaborativa en el período agosto-octubre 2018.

Esta es una investigación descriptiva, longitudinal, con una muestra seleccionada deforma no probabilística, por conveniencia, de193 alumnos pertenecientes a las carreras de Medicina, Kinesiología, Nutrición y Fonoaudiologíaque cursan la materia Metodología de la Investigación. Para alcanzar lo propuesto los alumnos participaron en una serie de actividades que favorecen el pasaje de la mirada disciplinar a la interdisciplinar en el abordaje de la temática "Tuberculosis", conla gesta de un problema de investigacióncomo resultado del proceso realizado. El tránsito que realizan los alumnos al pasar de una fase a 


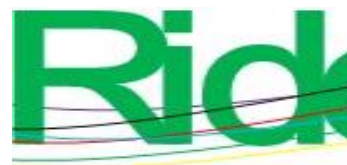

Revista Iberoamericana para la Investigación y el Desarrollo Educativo

ISSN $2007-7467$

otra queda plasmado en la tela de araña, estrategia implementada desde un documento compartido que permite que los estudiantes trabajen en forma asincrónica colaborativamente, y que sean monitoreados por la docente. Esto permite también visibilizarlas entregas,los avances, los intercambios y acuerdos realizados en los grupos de trabajo.

La fluidez con que se mueve el conocimiento científico actualmente requiere una permanente revisión de prácticas que favorezcan la enseñanza y aprendizaje de los diversos contenidosque se deben desarrollar en una cátedra universitaria. El elaborar un problema de investigación es uno de los pasos claves. Todo paciente debe ser atendido de forma integral y esto exige un entrenamiento en el trabajo interdisciplinario por parte de quienes cursan carreras en ciencias médicas.

Palabras claves:ciencias médicas,colaborativa, estrategia educativa, interdisciplinaria, problema de investigación.

\section{Abstract}

The search for activities that promote collaborative work in students of the Chair of Research Methodology of the University Fraternity of Groups Santo Tomás de Aquino in the city of Mar del Plata, Argentina, is a permanent challenge. Therefore, it is proposed as an objective to analyze the use of strategies and resources selected by the holder of said course in the four careers of the Faculty of Medical Sciences so that students formulate an interdisciplinary and collaborative research problem in the August-October period 2018.

This is a descriptive, longitudinal investigation, with a selected sample that is not probabilistic, for convenience, of 193 students belonging to the Medicine, Kinesiology, Nutrition and Phonoaudiology careers who study the subject Research Methodology. In order to achieve what was proposed, the students participated in a series of activities that favor the passage of the disciplinary perspective to the interdisciplinary approach in the approach of the topic "Tuberculosis", with the development of a research problem as a result of the process carried out. The transit that students make when moving from one phase to another is embodied in the spider web, a strategy implemented from a shared document that allows students to work collaboratively asynchronously, and be monitored 


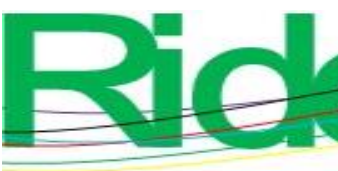

Revista Iberoamericana para la Investigación y el Desarrollo Educativo

ISSN $2007-7467$

by the teacher. This also makes visible deliveries, advances, exchanges and agreements made in the working groups.

The fluidity with which scientific knowledge moves currently requires a permanent review of practices that favor the teaching and learning of the various contents that must be developed in a university chair. Developing a research problem is one of the key steps. Every patient must be treated comprehensively and this requires training in interdisciplinary work by those who pursue careers in medical sciences.

Keywords:medical sciences, collaborative, educational strategy, interdisciplinary, research problem.

\section{Resumo}

A busca de atividades que promovam o trabalho colaborativo em alunos da Cátedra de Metodologia de Pesquisa da Fraternidade Universitária de Grupos Santo Tomás de Aquino, na cidade de Mar del Plata, Argentina, é um desafio permanente. Portanto, propõe-se como objetivo analisar o uso de estratégias e recursos selecionados pelo titular do curso nas quatro carreiras da Faculdade de Ciências Médicas, para que os alunos formem um problema de pesquisa interdisciplinar e colaborativa no período de agosto a outubro 2018.

Trata-se de uma investigação descritiva, longitudinal, com amostra selecionada não probabilística, por conveniência, de 193 estudantes pertencentes às carreiras de Medicina, Cinesiologia, Nutrição e Fonoaudiologia que estudam a disciplina Metodologia da Pesquisa. Para alcançar o que foi proposto, os alunos participaram de uma série de atividades que favorecem a passagem da perspectiva disciplinar para a abordagem interdisciplinar na abordagem do tópico "Tuberculose", com a ação de um problema de pesquisa em decorrência do processo realizado. O trânsito que os alunos fazem ao passar de uma fase para outra se reflete na teia de aranha, uma estratégia implementada a partir de um documento compartilhado que permite que os alunos trabalhem colaborativamente de forma assíncrona e sejam monitorados pelo professor. Isso também torna visíveis entregas, avanços, trocas e acordos feitos nos grupos de trabalho.

A fluidez com que o conhecimento científico se move atualmente exige uma revisão permanente de práticas que favorecem o ensino e a aprendizagem dos vários conteúdos que devem ser desenvolvidos em uma cátedra universitária. Desenvolver um problema de 


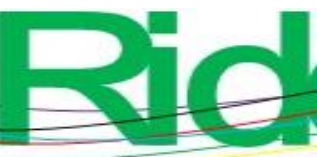

Revista Iberoamericana para la

Investigación y el Desarrollo Educativo

ISSN $2007-7467$

pesquisa é uma das etapas principais. Todo paciente deve ser tratado de maneira abrangente e isso requer treinamento em trabalho interdisciplinar por aqueles que seguem carreiras nas ciências médicas.

Palavras-chave:ciências médicas, colaboração, estratégia educacional, interdisciplinar, problema de pesquisa.

Fecha Recepción: Abril 2019

Fecha Aceptación: Diciembre 2019

\section{Introducción}

Año a año el equipo docentede la cátedra de Metodología de la Investigaciónde la Facultad de Ciencias Médicas de Universidad Fraternidad de Agrupaciones Santo Tomás de Aquino(Fasta) de la ciudadde Mar del Plata, Argentina, analiza estrategiasque faciliten el acercamiento de los alumnosa lo que implica investigar. Siguiendo a López (2011, pp. 286-287),se inicia un movimiento para quese conjuguen e hibridensaberes y habilidades incorporados y fortalecidos durante la cursada. ${ }^{1}$

El objetivo del presente trabajo fue analizar el uso de estrategias y recursos seleccionados por la titular de la cátedra de las cuatro carrerasde la facultad arriba mencionada para que los alumnos formulen un problema de investigación de manerainterdisciplinariacolaborativa en el período agosto-octubre 2018

Es importante presentar la definición seleccionada por Esteban, Tosina, Delgado y Fustes (2011), quienes citan a Lara (2001): "El aprendizaje colaborativo podría definirse como una 'filosofía'que implica y fomenta trabajar, construir, aprender, cambiar y mejorar, pero juntos" (p. 184).

Para poder comprenderel producto alcanzado es necesario, asimismo, presentar el contexto en el que seprogramaron las actividades de la cátedra.

Lamisma se organiza bajo la modalidad de b-Learning.Bartolomé (2004, pp. 1114)haceun amplio análisis de lo que implica esta modalidad, que combinapresencialidad yvirtualidad, asociándolas a los grandes cambios que se handesencadenado no solo por el uso de las nuevas tecnologías, sino por el impacto en lo social.En la modalidad presencialla acreditación se realiza con la aprobación del primer y el segundo parcial deforma individual, mientras que el tercer parcialconsiste en la presentación de unprotocolode

\footnotetext{
${ }^{1}$ Este autor, en su artículo sobre la formación de competencias en la enseñanza universitaria, hace referencia a un "giro copernicano" en el nuevo enfoque que propone para el nivel superior.
} 


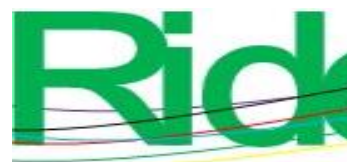

Revista Iberoamericana para la Investigación y el Desarrollo Educativo

ISSN $2007-7467$

investigaciónen elAteneo Joven de Investigaciónfrente a sus compañerosy alumnos de otras carreras. La evaluación de esa instanciaestá a cargo deuna dupla de docentes especialistas en la disciplina, a quienes se les entrega una grilla de evaluación para unificar criterios seleccionados.

En la modalidad presencial se brindamaterialteórico para acompañar a los alumnos en el desarrollo grupal de un protocolo original, con un monitoreo permanente de sus avances, y se realizanlos ajustes necesarios producto de las reflexiones compartidas. Eseprotocolo se presenta en el mes de octubre en elencuentro líneas arriba mencionado. En los primeros cinco añossolo participaron los estudiantes de la Licenciatura en Nutrición, Licenciaturaen Kinesiología y Licenciatura en Fonoaudiología. En el 2018,en el VI Ateneo Joven de Investigación, dependiente dela cátedra,se sumó la carrera de Medicina. A continuación, se presenta un gráfico que permite visibilizar los alumnos que ingresaron a la cátedra en el 2018.

Figura 1.Alumnos ingresantes ala cátedra de Metodología de la Investigaciónsegún carrera

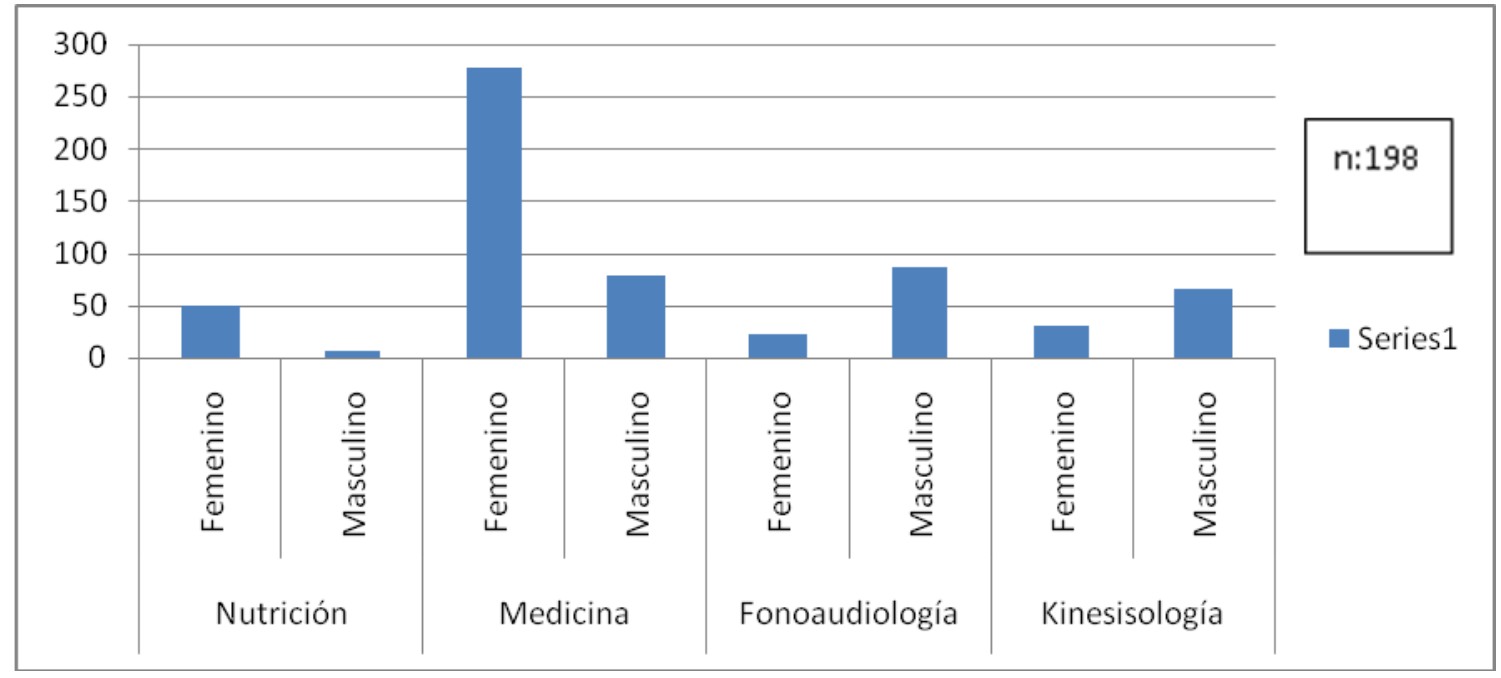

Fuente: Elaboración propia

Con la participación de 193 de los 198estudiantes, se presentan 42trabajosen 3salas simultáneas. A manera de ejemplo semencionanalgunos de los temas seleccionados por los alumnos de la cátedra de Metodología en elVI Ateneo Joven de la Investigación: Prevalencia de hipertensión y su relación con la ingesta de sal y sodio contenido en los alimentos; Estado nutricional, ingesta alimentaria, tipo y estadio de cáncer en pacientes que asisten al Centro de Oncología;Rehabilitación kinésica en ruptura de LCA y dolor en 


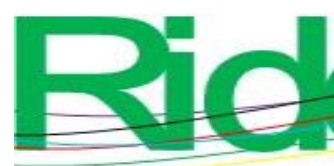

Revista Iberoamericana para la

Investigación y el Desarrollo Educativo

ISSN $2007-7467$

futbolistas;Lumbalgia, cefalea tensional y cervicalgia en estudiantes de Ciencias Médicas, y La voz en jugadores de futbol.

Para el desarrollo de las actividades virtualesse emplea el aula virtualde la plataforma de la universidad.Estos espacios dedicados al aprendizaje virtual hacen posiblela participación asincrónicay el trabajo de personas que cursan en distintas ubicaciones espaciales y temporales, ya que las cursadas de las cuatro carreras no coinciden en horarios ni enlos días de semana.

En la modalidad virtual se proponen tres actividades a desarrollar durante el año de forma colaborativa. El aprendizaje en ambientes colaborativos busca propiciar espacios en los cuales se dé el desarrollo de habilidades individuales y grupales a partir de la discusión entre los estudiantes al momento de explorar nuevos conceptos, siendo cada quien responsable de su propio aprendizaje (Lucero, 2003, p. 3).

- $\quad$ Primera actividad: Caza del tesoro ${ }^{2}$ sobre ciencia, conocimiento científico, ciencia básica, ciencia aplicada, contextos de descubrimiento, de validación, de aplicación, $\mathrm{I}+\mathrm{D} ; \mathrm{I}+\mathrm{D}+\mathrm{i} .^{3}$

- $\quad$ Segunda actividad: Participación en una wiki ${ }^{4}$ sobre CTS, ciencia tecnología. Indicadores. Megabuscadores de revistas académicas

- $\quad$ Tercera actividad:La misma se realiza en simultáneo entre las cuatro carreras paraabordaje interdisciplinario de una temática, en esta oportunidad "Tuberculosis".

Tamayo (2004) señala como uno de los objetivos de la interdisciplinariedad lo puesto a continuación:"Fomentar una integración de las ciencias particulares(disciplinas) en la solución de problemas reales"(p. 84).

Posada (2008:27) por su parte, menciona que "la interdisciplinariedad busca la articulación de disciplinasque no son del mismo campo. Los diferentes objetos y objetivos académicos de un grupo de disciplinas se ven integrados en relaciones de intercambio de conocimientos que permiten solucionar problemas de la sociedad".

\footnotetext{
${ }^{2}$ Los datos de la Caza del tesoro, con el nombre de "Percepción sobre competencias que se fortalecen al implementar una Caza del Tesoro de Ciencia y Conocimiento Científico", resultantes de las actividades virtuales desarrolladas en 2016 han sido presentados en el VI Congreso Internacional de Competencias Laborales (Coincom), llevado a cabo en Cartagena de Indias, 2017.

${ }^{3}$ Este trabajo fue aceptado en formato virtual y fue denominado "Iniciando la mirada en Política Científica en la cátedra de Metodología de la Investigación" presentado por Vivian Minnaard y Claudia Minnaard en el XXV Congreso Internacional de Aprendizaje, llevado a cabo del 21-23 de junio de 2018enAtenas.

${ }^{4} \mathrm{Si}$ desea ampliar la información sobre lo que implica una wikise sugiere consultarGonzález, F. S. (2005, October). Herramientas colaborativas para la enseñanza usando tecnologías web: weblogs, redes sociales, wikis, web 2.0. In Simposio llevado a cabo en la conferencia de la Universidad de León.
} 


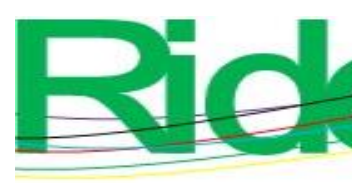

Revista Iberoamericana para la Investigación y el Desarrollo Educativo ISSN $2007-7467$

Pero el pasaje de la disciplinariedad a la interdisciplinariedad no es algo automático;es necesario que los alumnos transiten etapas o, como se denominan en esta oportunidad,fases. En esta publicación se presentan los resultados de la tercera actividad virtual

\section{Método}

Se trata de una investigación descriptiva, longitudinal, con una muestra seleccionada deforma no probabilística, por conveniencia, de193 alumnos pertenecientes a las carreras de Medicina, Kinesiología, Nutrición y Fonoaudiología

\section{Desarrollo}

El total de alumnos (193) que tenían el porcentaje esperable de asistencia para poder acreditarse dividióen 10 grupos; encada uno participaron alumnos de las cuatro carreras para resolver las actividades propuestasy concluir con la formulación de un problema interdisciplinar.

Figura 2. Agrupaciones de alumnos para la experiencia

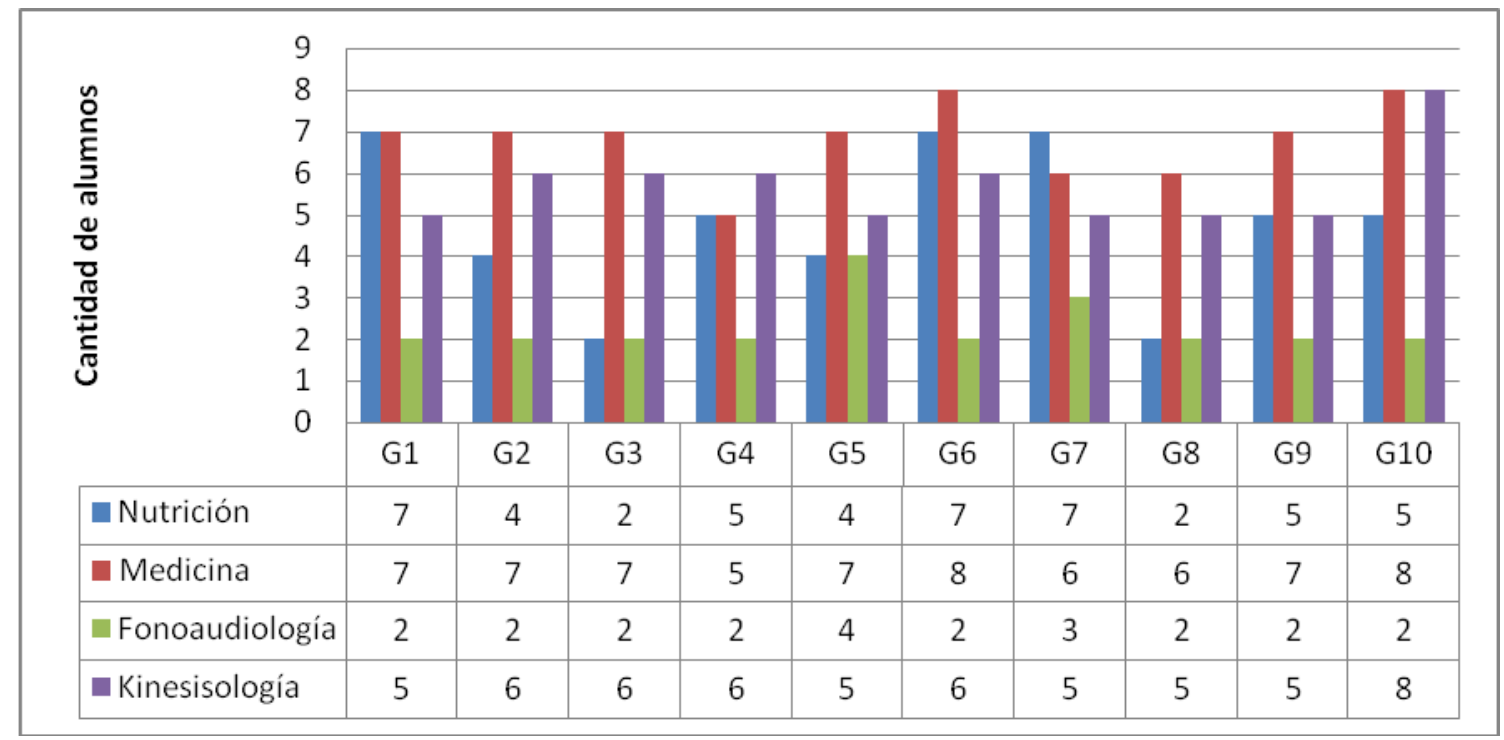

Fuente: Elaborado propia 


\section{Fase 1}

Se propone en el aula virtualla lectura de la página23y 24del documentoLa Agenda 2030 y los Objetivos de Desarrollo Sostenible.Una oportunidadpara América Latina y el Caribe(Organización de las Naciones Unidas [ONU], 2018), que indica que "de aquí a 2030, poner fin a las epidemias del SIDA, la tuberculosis, la malariay las enfermedades tropicales desatendidas y combatir la hepatitis, las enfermedades transmitidas por el agua y otras enfermedades transmisibles" (p. 24). Estojunto con un artículo de un diario online queindica que han crecido notablemente los casos de tuberculosis en la ciudad de Mar del Plata, Argentina. ${ }^{5}$

Seimplementa la técnica brainstorming ${ }^{6}$ con los alumnos,quienescompletan la grilla con tres conceptos asociados a la tuberculosisen sus respectivas disciplinas, los cuales no se pueden repetir con losseleccionados porsus compañeros

Se sugiere la lectura de Editorial'Preocupan casos de tuberculosis en Mar del Plata Es una enfermedad que volvió a emerger" [Editorial] (8 de enero de 2018) 0223, Recuperado de : https://www.0223.com.ar/nota/2018-1-8-14-10-0preocupan-los-casos-de-tuberculosis-en-mar-del-plata-es-una-enfermedad-que-volvio-a-emerger ${ }^{6}$ Esta técnica de creatividad tan difundida suele conocerse también en español como lluvia de ideas, yse le atribuye a Alex FaickneyOsborn su creación. 
Tabla 1.Conceptos seleccionados por los alumnos sobre la tuberculosis

\begin{tabular}{|c|c|c|c|c|}
\hline & Alumno & $\mathbf{A}$ & $\mathbf{B}$ & $\mathrm{C}$ \\
\hline \multirow[t]{4}{*}{ Nutrición } & $\mathrm{A}$ & $\begin{array}{l}\text { Diagnóstico } \\
\text { pulmonar }\end{array}$ & $\begin{array}{l}\text { Prevención de la } \\
\text { enfermedad }\end{array}$ & $\begin{array}{l}\text { Mayor prevalencia } \\
\text { de varones }\end{array}$ \\
\hline & $\mathrm{B}$ & $\begin{array}{l}\text { Debilidad del } \\
\text { sistema inmune }\end{array}$ & $\begin{array}{l}\text { Control de peso } \\
\text { periódicamente }\end{array}$ & $\begin{array}{l}\text { Disnea, dificultad } \\
\text { en la respiración }\end{array}$ \\
\hline & $\mathrm{C}$ & $\begin{array}{l}\text { Transmisión, } \\
\text { inhalación de } \\
\text { pequeñas gotas } \\
\text { expelidas al toser }\end{array}$ & $\begin{array}{l}\text { Síntomas, sudores } \\
\text { nocturnos, pérdida de } \\
\text { peso }\end{array}$ & Terapia \\
\hline & $\mathrm{D}$ & $\begin{array}{l}\text { Problema de } \\
\text { salud pública }\end{array}$ & Aparato respiratorio & Apoyo nutricional \\
\hline \multirow[t]{7}{*}{ Medicina } & $\mathrm{E}$ & $\begin{array}{l}\text { Test } \\
\text { especializado }\end{array}$ & Hemoptisis & $\begin{array}{l}\text { Tuberculosis } \\
\text { extrapulmonar }\end{array}$ \\
\hline & $\mathrm{F}$ & Agente causal & Diseminación & $\begin{array}{l}\text { Reversible con } \\
\text { tratamientocombin } \\
\text { ado } \\
\text { adecuado } \\
\text { prolongado }\end{array}$ \\
\hline & G & $\begin{array}{l}\text { Afección lóbulos } \\
\text { apicales }\end{array}$ & Hacinamiento & $\begin{array}{l}\text { Leucocitosis } \\
\text { linfocitaria }\end{array}$ \\
\hline & $\mathrm{H}$ & $\begin{array}{l}\text { Primera causa de } \\
\text { muerte por } \\
\text { enfermedad } \\
\text { infecciosa }\end{array}$ & Latente o adquirida & Fisiopatología \\
\hline & I & Pulmones & Infección & Bacteria \\
\hline & $\mathrm{J}$ & $\begin{array}{l}\text { Exposición al } \\
\text { bacilo }\end{array}$ & Diseminación & Diagnóstico precoz \\
\hline & $\mathrm{K}$ & Bacilo & Inmunodeficiencia & Contagio \\
\hline \multirow[t]{2}{*}{$\begin{array}{l}\text { Fonoau- } \\
\text { Diología }\end{array}$} & $\mathrm{L}$ & $\begin{array}{l}\text { Patrón } \\
\text { respiratorio }\end{array}$ & Voz disfuncional & Laringoscopia \\
\hline & $\mathrm{M}$ & Habla & Respiración & Musculatura oral \\
\hline \multirow[t]{4}{*}{$\begin{array}{l}\text { Kinesio- } \\
\text { logía }\end{array}$} & $\mathrm{N}$ & $\begin{array}{l}\text { Alteraciones en } \\
\text { espirómetro }\end{array}$ & $\begin{array}{l}\text { Rehabilitación } \\
\text { pulmonar }\end{array}$ & Dolor de espalda \\
\hline & $\mathrm{O}$ & $\begin{array}{l}\text { Precauciones en } \\
\text { el tratamiento } \\
\text { por parte del } \\
\text { profesional }\end{array}$ & $\begin{array}{l}\text { Situación social del } \\
\text { paciente afectado }\end{array}$ & $\begin{array}{l}\text { Maniobras } \\
\text { kinesiológicas } \\
\text { respiratorias } \\
\text { adecuadas al } \\
\text { tratamiento de la } \\
\text { tuberculosis }\end{array}$ \\
\hline & $\mathrm{P}$ & Restrictiva & $\begin{array}{l}\text { Clínica, tos crónica con } \\
\text { esputo sanguinolento, } \\
\text { fiebre, sudoración } \\
\text { nocturna y pérdida de } \\
\text { peso }\end{array}$ & $\begin{array}{l}\text { Prevención y } \\
\text { control en la } \\
\text { progresión clínica } \\
\text { del paciente }\end{array}$ \\
\hline & Q & $\begin{array}{l}\text { Ventilación } \\
\text { mecánica }\end{array}$ & Epidemiología & Palpación \\
\hline
\end{tabular}

Fuente: Elaborado por alumnos que asisten a la cátedra de Metodología 


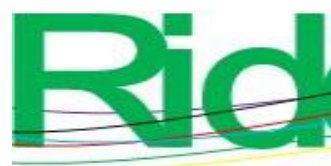

Revista Iberoamericana para la Investigación y el Desarrollo Educativo

ISSN $2007-7467$

Esta actividad permite establecer la relación con lo que Angulo (2017, p.58-59) hace al citar el modelo deNonaka y Takeuchi (1995),con el pasaje del conocimiento tácito que cada estudiante poseía, al comenzar lafase 1,a un conocimiento explícito, compartiéndolo con el grupo con el que está realizando esta actividad. Cabe recordarque el conocimiento tácito es propio de la persona, mientras que el explícitose exterioriza. Y se identifica dentro de este tránsito un movimiento de "tácito a tácito",es decir,que comienzan a “adquirir conocimientos a partir del compartir” (Sánchez, 2005, párr. 20).

\section{Fase 2}

Se les indica a los estudiantes queseleccionen un solo concepto de entre todos los que proponen sus compañeros de grupo que justifiquen su elección. Para ejemplificar esto, la tabla 2 muestra cómo respondieron a esta consigna los alumnos de la Lic. en Nutrición del grupo 9. En esta etapa se percibe que se inicia un tránsito mucho más dinámico, comenzando a tomar decisiones que conducen a posicionamientos reflexivos. 
Tabla 2.Justificación de conceptos seleccionados por alumnos de la carrera de Lic. en

Nutrición

\begin{tabular}{|l|l|l|}
\hline Alumnos & Conceptoelegido & Justificación de la elección \\
\hline A & Apoyo nutricional & $\begin{array}{l}\text { En mi opinión, considero, desde el rol del nutricionista, de } \\
\text { suma importancia el apoyo nutricional. La enfermedad de } \\
\text { tuberculosis tiene como uno de los principales síntomas la } \\
\text { falta de apetito, dando como consecuencia la } \\
\text { malnutrición,lo que puede llevar a la desnutrición, por lo } \\
\text { que el apoyo nutricional es fundamental. Este puede } \\
\text { suplementarsepor vía oral; sino presentan problemas } \\
\text { deglutorios, por vía enteral (en segunda instancia y, por } \\
\text { último, vía parenteral). }\end{array}$ \\
\hline B & Epidemiología & $\begin{array}{l}\text { En mi opinión, considero de suma importancia la } \\
\text { epidemiología, ya que es una ciencia que estudia el } \\
\text { desarrollo epidémico y la incidencia de las enfermedades } \\
\text { infecciosas en la población. La importancia de este estudio } \\
\text { tiene lugar en el desarrollo de estrategias preventivas. El } \\
\text { razonamiento epidemiológico tiene su centro en la } \\
\text { prevención se basa en el riesgo de la enfermedad. }\end{array}$ \\
\hline C & Dietoterapia & $\begin{array}{l}\text { En mi opinión, el rol del nutricionista es muy importante en } \\
\text { cuanto a este aspecto porque la malnutrición es uno de los } \\
\text { factores que aumentan el riesgo de padecer tuberculosis, ya } \\
\text { que, al disminuir las defensas, se produce una debilidad del } \\
\text { sistema inmune; en cambio, con una adecuada nutrición, el } \\
\text { sistema inmunológico opone una resistencia. }\end{array}$ \\
\hline D & $\begin{array}{l}\text { Creo que es importante la dietoterapia en pacientes que } \\
\text { padecen tuberculosis ya que es fundamental cómo se llevará } \\
\text { a cabo la alimentación en aquellos que padecen esta } \\
\text { enfermedad, debido a que esto influirá en su tratamiento. }\end{array}$ \\
\hline
\end{tabular}

Fuente: Elaborado sobre datos de la investigaciónpor alumnos de la cátedra de Metodología

Así, pues, en esta etapa se percibe el pasaje de tácito a explícito, situación indispensable para lograr la justificación de la elección (Sánchez, 2005).

\section{Fase 3}

Luego, los acuerdos que se comienzan a establecer. Se coloca un mensaje dirigido a los alumnos que los invitan a iniciar un camino con la intención de trabajar y empezar a pensar en forma interdisciplinaria.

En la tercera etapa se les presenta un diagrama diseñadopor la autora de esta investigación denominado tela de araña. ${ }^{7}$ Las telas de araña han despertado el interés de múltiples especialistas, no solo por sus partes, sino por su composición química, su

\footnotetext{
${ }^{7}$ La cantidad de secciones se deben de adaptar en el diagrama según la cantidad de disciplinas a las que pertenezcan las personas que participen en la experiencia y estas se debenmultiplicarpordos;por ejemplo, si fueran tres, las secciones de la tela de araña deberían ser seis.
} 

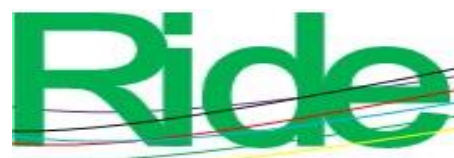

Revista Iberoamericana para la Investigación y el Desarrollo Educativo

ISSN $2007-7467$

geometría, su resistencia, y ha inspirado a matemáticos, arquitectos, diseñadores, entre otros

La figura 3 muestra ocho zonas bien delimitadas; cuatro de las cuales corresponden a cada una de las disciplinas indicadas con colores prefijados. En esas cuatro zonas se intercalan otras cuatro zonas intermedias, donde los alumnos ubicarán aquellos conceptos donde se comienzan a hibridar las disciplinas; en ese caso el concepto se remarca con los colores seleccionados para cada una de las disciplinas: nutrición, kinesiología, fonoaudiología medicina.

Figura 3. Estructura de la tela de araña

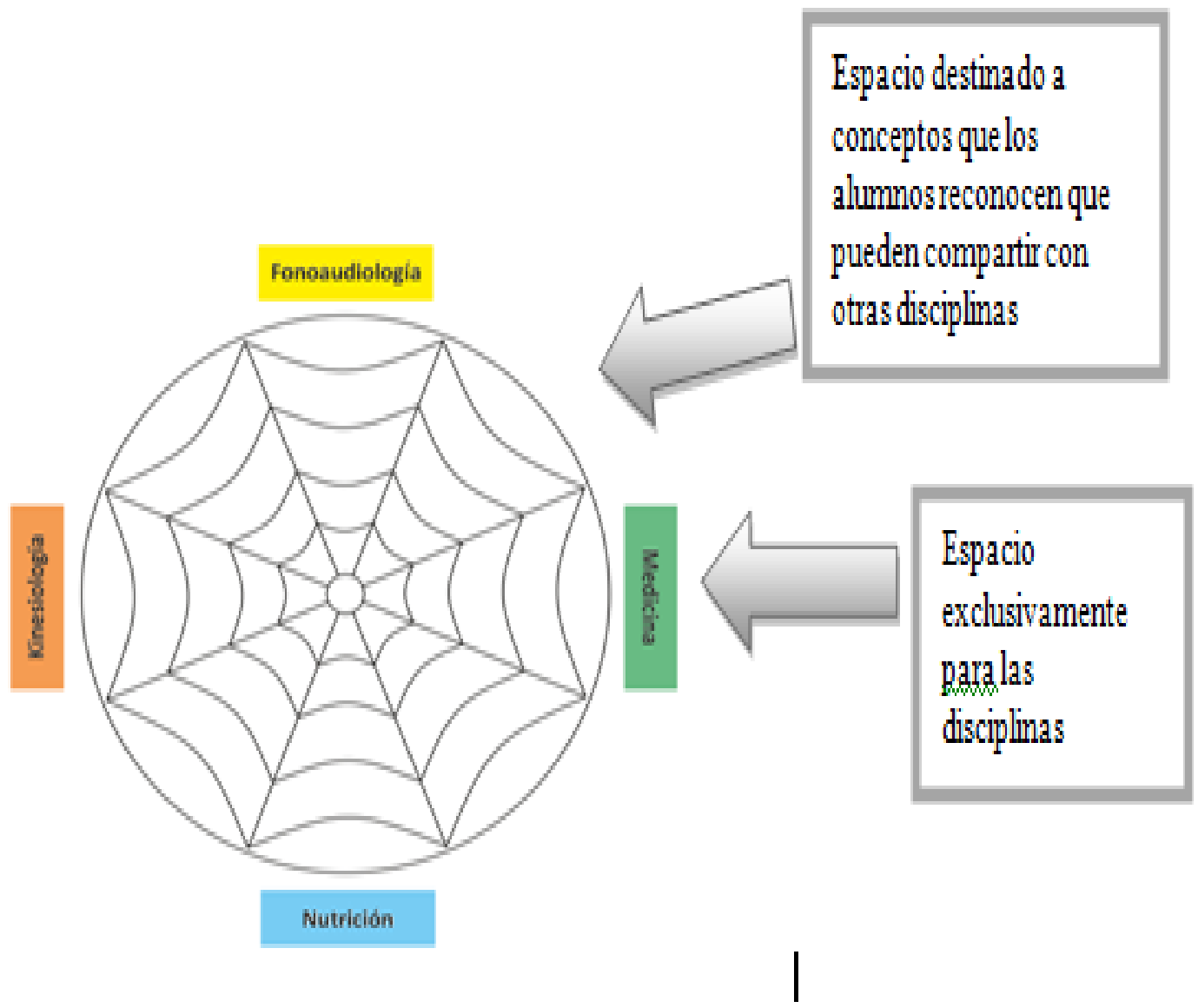

Fuente: Elaboración propia

El concepto tuberculosis se ubica deforma central en la tela de araña. Un aspecto importante considerares que los conceptos más significativos deben ir cerca del centro y los menos significativos más alejados. 

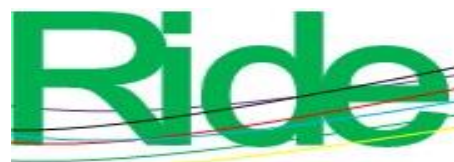

Revista Iberoamericana para la Investigación y el Desarrollo Educativo ISSN $2007-7467$

Los intercambios entre alumnos de distintas carreras quedan registrados Enel documento compartido, indicando nombre y apellido del estudiante que propone el concepto o acuerda con otro participante, justificando su elección debajo del diagrama de la tela de araña. A continuación, para ilustrar lo anterior, se presentan los resultados de las telas de araña del grupo 9. Se indican las tres entregas monitoreadas por la docente, dondese observa la evolución del intercambio y los acuerdos que se ven reflejados en el diagrama, lo que permite visualizar el pasaje de la disciplinariedad a la interdisciplinariedad

Figura 4. Primera entrega realizada por los alumnos del grupo 9

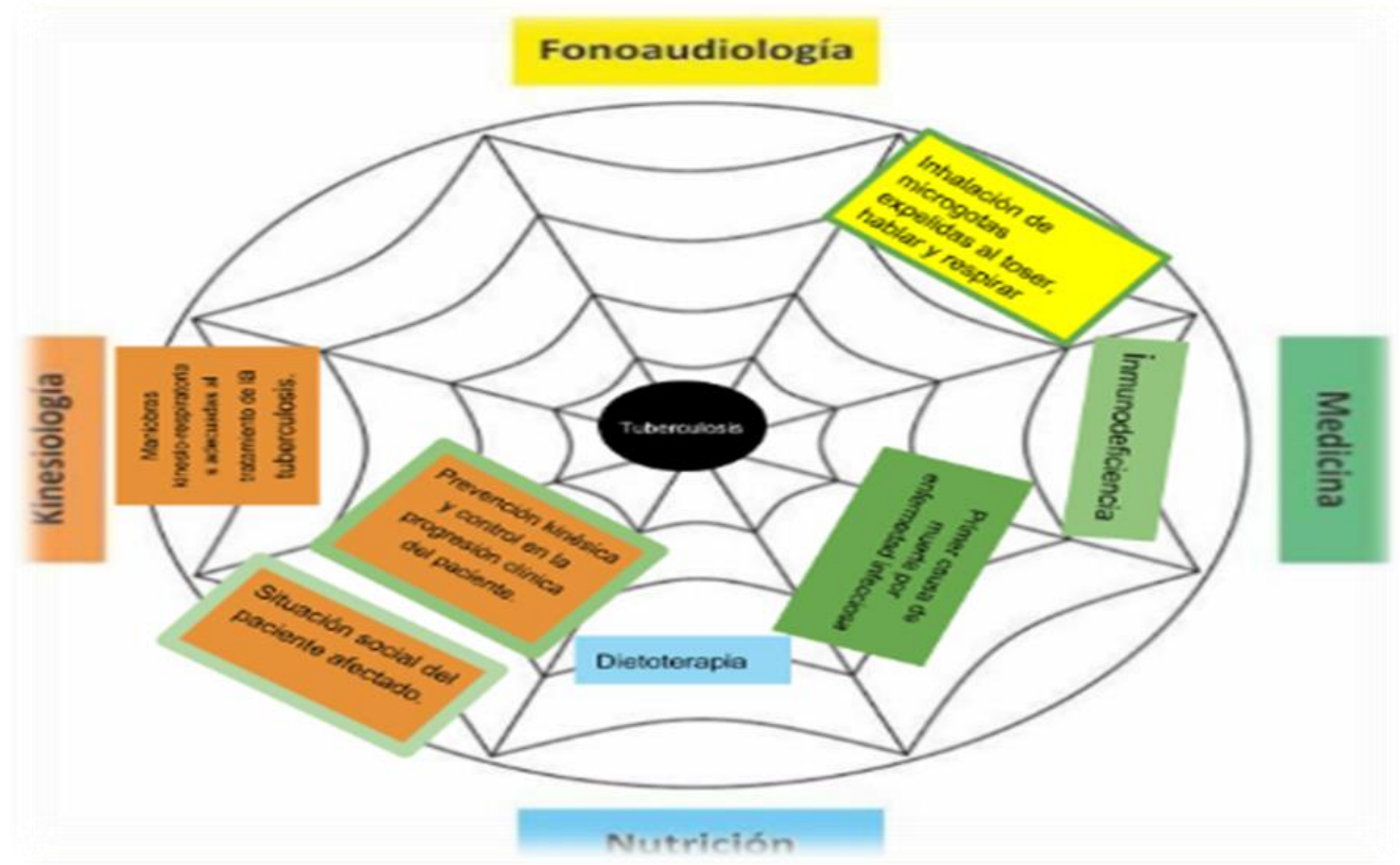

Fuente: Elaborado sobre datos de la investigación por alumnos de la cátedra de Metodología 

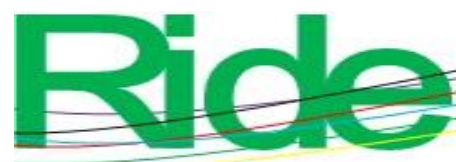

Revista Iberoamericana para la Investigación y el Desarrollo Educativo ISSN $2007-7467$

Figura 5. Segunda entrega realizada por los alumnos delgrupo 9

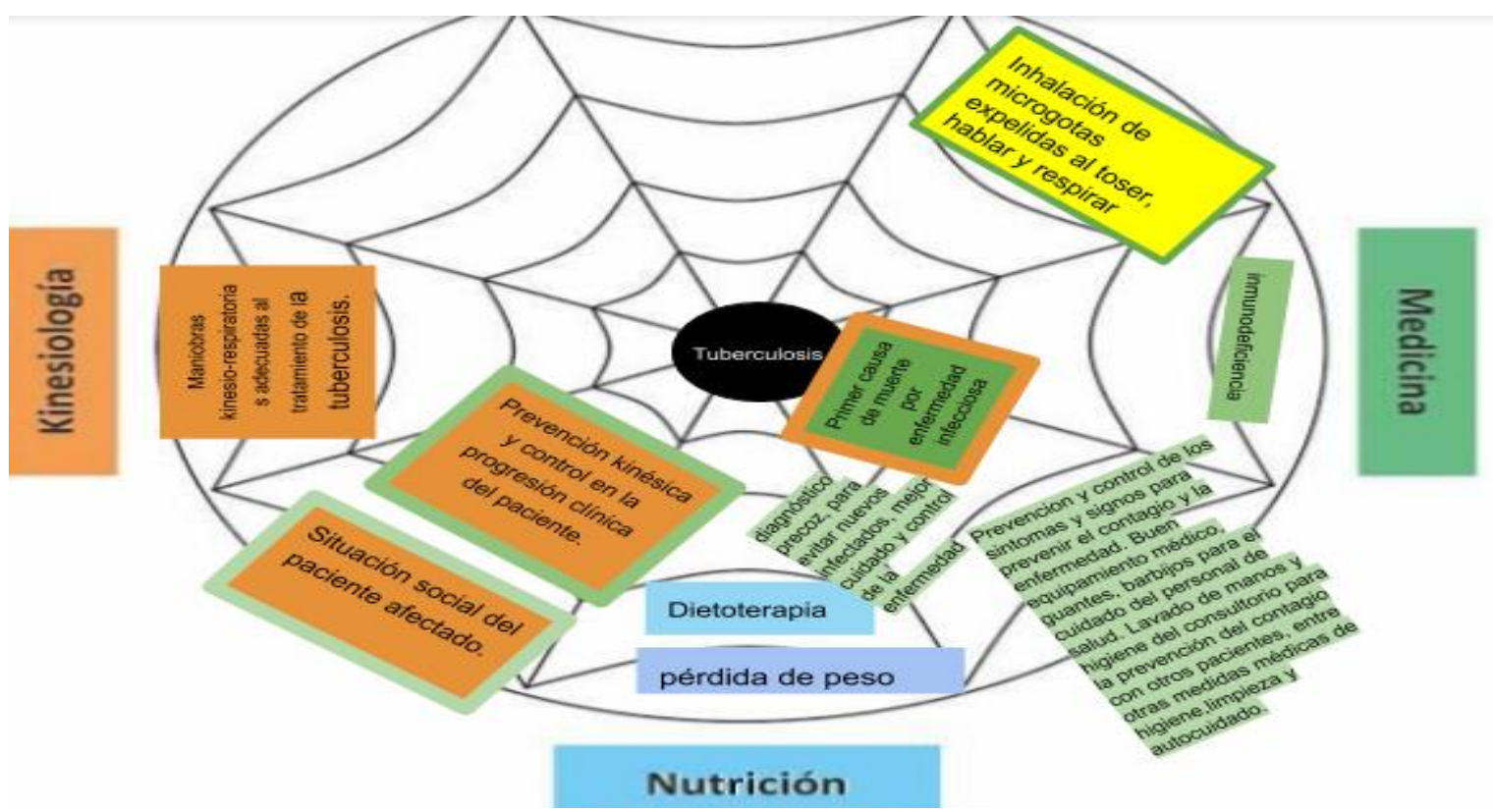

Fuente: Elaborado sobre datos de la investigación por alumnos de la cátedra de

Metodología

Figura 6. Tercera entrega realizada por los alumnos delgrupo 9

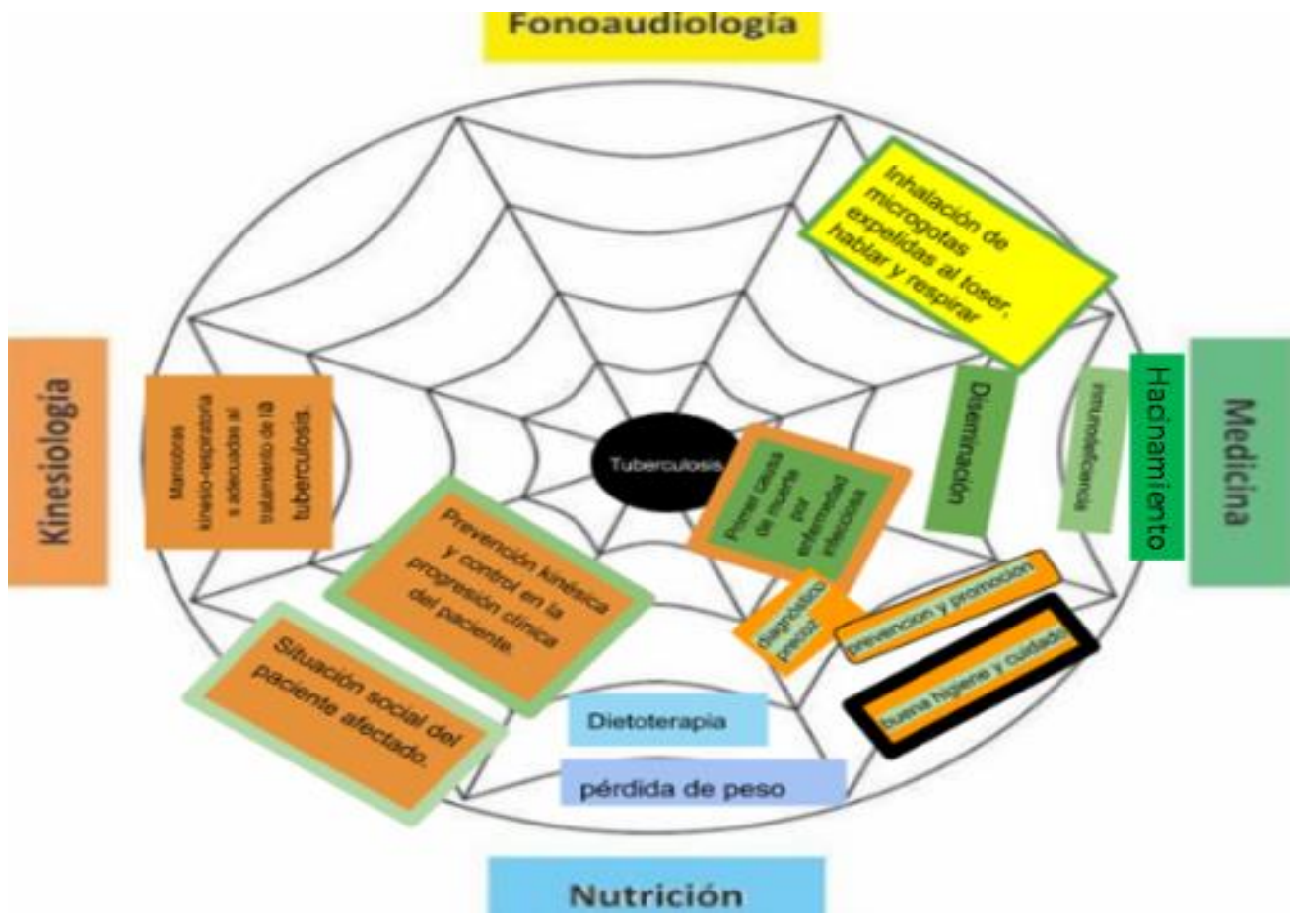

Fuente: Elaborado sobre datos de la investigación por alumnos de la cátedra de Metodología 
Se puede observar que medida que se van realizando las entregas losavances reflejan los intercambios y acuerdos realizados en los grupos de trabajo. Lo cual permiteidentificaraquellos conceptos que reconocen que podrían compartir. En este organizador gráfico se representa el producto de la tercera tela de araña del grupo 9, que permite ver las relaciones que se establecen. Por ejemplo, los alumnos de la Lic. en Medicina indicaron que la "Inhalación de pequeñas gotas expelidas al toser, hablar y respirar", propuesto por alumnos de la carrera de Fonoaudiología, era un aspecto abordado también desde su especialidad. Por eso el concepto se remarca con los colores que identifican a cada disciplina. Estoles hace pensar que ante un paciente con estas características el tratamiento requeriría de las dos miradas.

Figura 7. Relaciones que los alumnos establecen sobre la tuberculosis

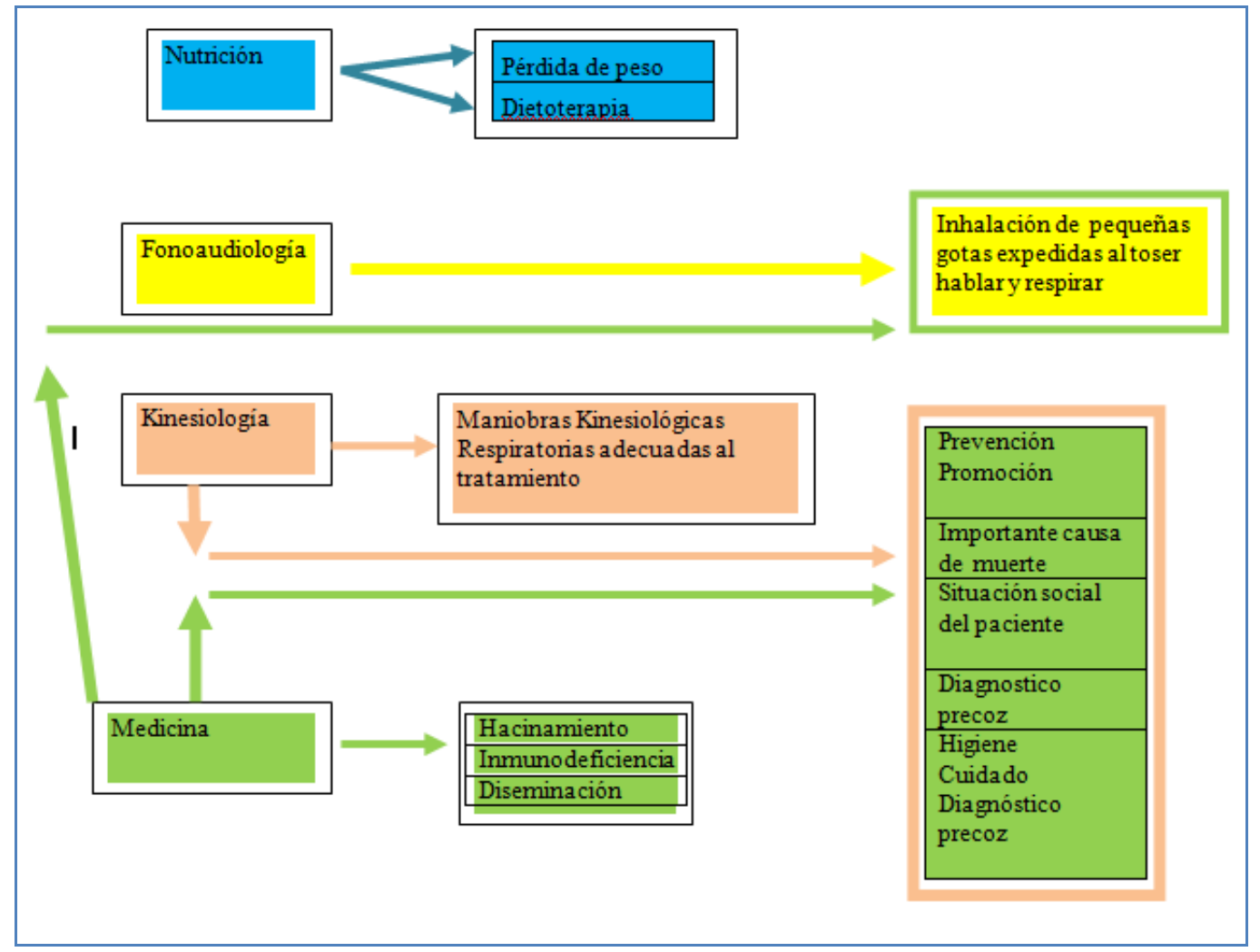

Fuente: Elaboración propia

A continuación, se analiza encada uno de los grupos el número de conceptos que los alumnos reconocen asociados a su disciplina. 
Figura 8. Número de conceptos indicados en forma disciplinar en el diagrama

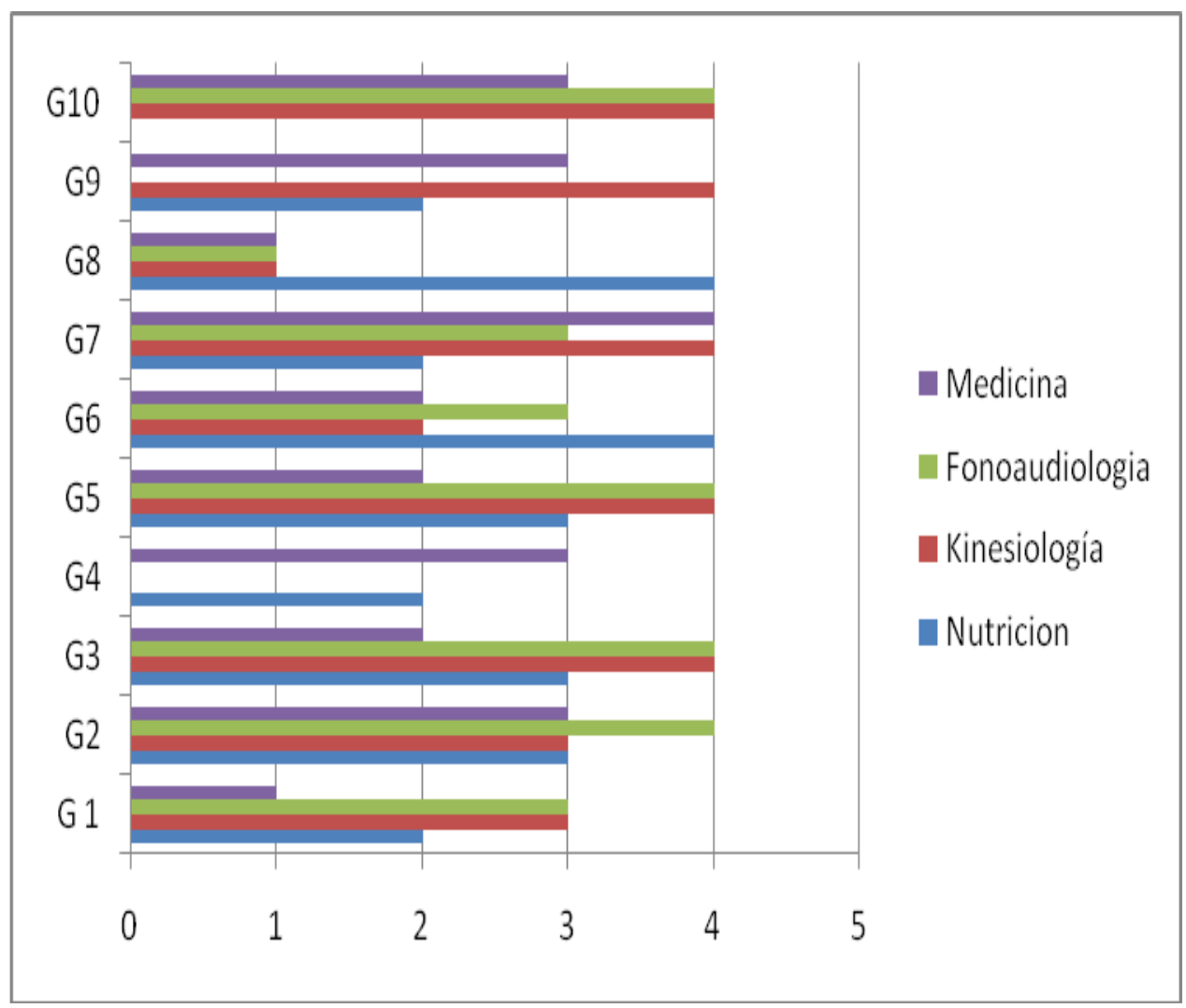

Fuente: Elaborado sobre datos de la investigación por alumnos de la cátedra de

\section{Metodología}

En la figura 8 se refleja quelos alumnos de las carreras de Kinesiología y Fonoaudiología son los que más conceptos disciplinarios mantienen

Posteriormente se analizan en los 10 grupos de trabajo aquellos conceptos que los alumnos reconocen que se pueden abordar desde distintas disciplinas, es decir,con qué conceptosentrecruzaron miradas y posibles formas de abordaje en un futuro equipo de salud. 
Tabla 3.Conceptossobre tuberculosisque los alumnos de distintas disciplinas comienzan a relacionar

\begin{tabular}{|c|c|c|c|c|c|c|c|c|}
\hline $\mathbf{G}$ & N-F & N-M & N-K & M-F & M-K & M-K-N & K-F & M-K-F \\
\hline 1 & $\begin{array}{c}\text { Disgluci } \\
\mathrm{a}\end{array}$ & $\begin{array}{c}\text { Bacterias } \\
\text { vacuna }\end{array}$ & $\begin{array}{c}\text { Hábitos } \\
\text { alimentarios } \\
\text { y de vida }\end{array}$ & $\begin{array}{l}\text { Laringitis } \\
\text { aguda } \\
\text { Prevenció } \\
\mathrm{n} \text { de } \\
\text { lesiones } \\
\text { de la vida } \\
\text { aérea }\end{array}$ & $\begin{array}{l}\text { Bacilo de } \\
\text { Koch }\end{array}$ & $\begin{array}{l}\text { Detección } \\
\text { temprana }\end{array}$ & & \\
\hline 2 & & $\begin{array}{l}\text { Pérdida de } \\
\text { peso }\end{array}$ & & & $\begin{array}{c}\text { Tos } \\
\text { productiva } \\
\text { Vacunació } \\
n\end{array}$ & & $\begin{array}{l}\text { Reeducación } \\
\text { respiratoria }\end{array}$ & \\
\hline 3 & & & & & Fisiología & & & \\
\hline 4 & & $\begin{array}{c}\text { Suplemento } \\
\text { s } \\
\text { nutricionale } \\
\text { s }\end{array}$ & $\begin{array}{c}\text { Contagio } \\
\text { Falta de } \\
\text { apetito } \\
\text { Transmisión } \\
\text { aérea }\end{array}$ & & $\begin{array}{l}\text { Sistema } \\
\text { inmunitario } \\
\text { Infección } \\
\text { pulmonar }\end{array}$ & & $\begin{array}{c}\text { Expectoració } \\
n \\
\text { Alteraciones } \\
\text { por patrón } \\
\text { respiratorio } \\
\text { Fatiga }\end{array}$ & \\
\hline 5 & & $\begin{array}{l}\text { Tuberculosi } \\
\text { s miliar }\end{array}$ & & Tos & & & $\begin{array}{c}\text { Rehabilitació } \\
\text { n pulmonar } \\
\text { Sonidos } \\
\text { respiratorios }\end{array}$ & $\begin{array}{c}\text { Patrón } \\
\text { respiratorio }\end{array}$ \\
\hline 6 & & OMS & & & $\begin{array}{c}\text { Prevención } \\
\text { primaria }\end{array}$ & & $\begin{array}{c}\text { Rehabilitació } \\
\text { n correcta } \\
\text { Dificultades }\end{array}$ & \\
\hline 7 & & & & & & $\begin{array}{c}\text { Prevenció } \\
\mathrm{n}\end{array}$ & Auscultación & \\
\hline 8 & & $\begin{array}{l}\text { Enfermedad } \\
\text { contagiosas }\end{array}$ & $\begin{array}{c}\text { Expectoració } \\
\mathrm{n} \\
\text { Malnutrición }\end{array}$ & & $\begin{array}{l}\text { Bacilo de } \\
\text { Koch } \\
\text { Tos } \\
\text { Epidemia }\end{array}$ & & $\begin{array}{c}\text { Patrón } \\
\text { respiratorio }\end{array}$ & $\begin{array}{l}\text { Rehabilitació } \\
\text { n respiratoria }\end{array}$ \\
\hline 9 & & & & $\begin{array}{c}\text { Inhalación } \\
\text { de } \\
\text { pequeñas } \\
\text { gotas }\end{array}$ & $\begin{array}{l}\text { Prevención } \\
\text { Promoción } \\
\text { Control de } \\
\text { laprogresió } \\
\text { n clínica } \\
\text { Situación } \\
\text { social del } \\
\text { paciente } \\
\text { Higiene } \\
\text { Diagnóstic } \\
\text { o precoz }\end{array}$ & & & \\
\hline $\begin{array}{l}\mathbf{1} \\
\mathbf{0}\end{array}$ & & $\begin{array}{c}\text { Sistema } \\
\text { inmune } \\
\text { Nutrición }\end{array}$ & $\begin{array}{l}\text { Pérdida de } \\
\text { peso }\end{array}$ & & $\begin{array}{l}\text { Vías aéreas } \\
\text { Disfagia } \\
\text { Diagnóstic } \\
\text { o precoz } \\
\end{array}$ & & & \\
\hline
\end{tabular}

Referencia: N: Licenciatura en Nutrición; F: Licenciatura en Fonoaudiología; K:

Licenciatura en Kinesiología; M: Medicina.

Fuente: Elaborado sobre datos de la investigación por alumnos de la cátedra de

\section{Metodología}




\section{Fase4}

A continuación, se presenta una adaptación del diagrama de Ishikawa, ${ }^{8}$ conocido muchas veces como espina de pescado o diagrama causa efecto, sumamente empleado para redireccionar decisiones futuras.

En la cabeza del pescado colocan un problema gestado y acordado por todo el grupo sobre la temática que se está trabajando, pero formulado como un problema de investigación, desde una mirada interdisciplinaria de un equipo de salud. Es el momento de abordar la realidad de esta manera. Es decir: analizada desde "el yo colectivo" (Tamayo y Tamayo, 2004, p. 83). Además, en las espinas colocan por lo menos 10 causas que perciben.

Figura 9. Diagrama espinas de pescado sobre la tuberculosis con abordaje interdisciplinario

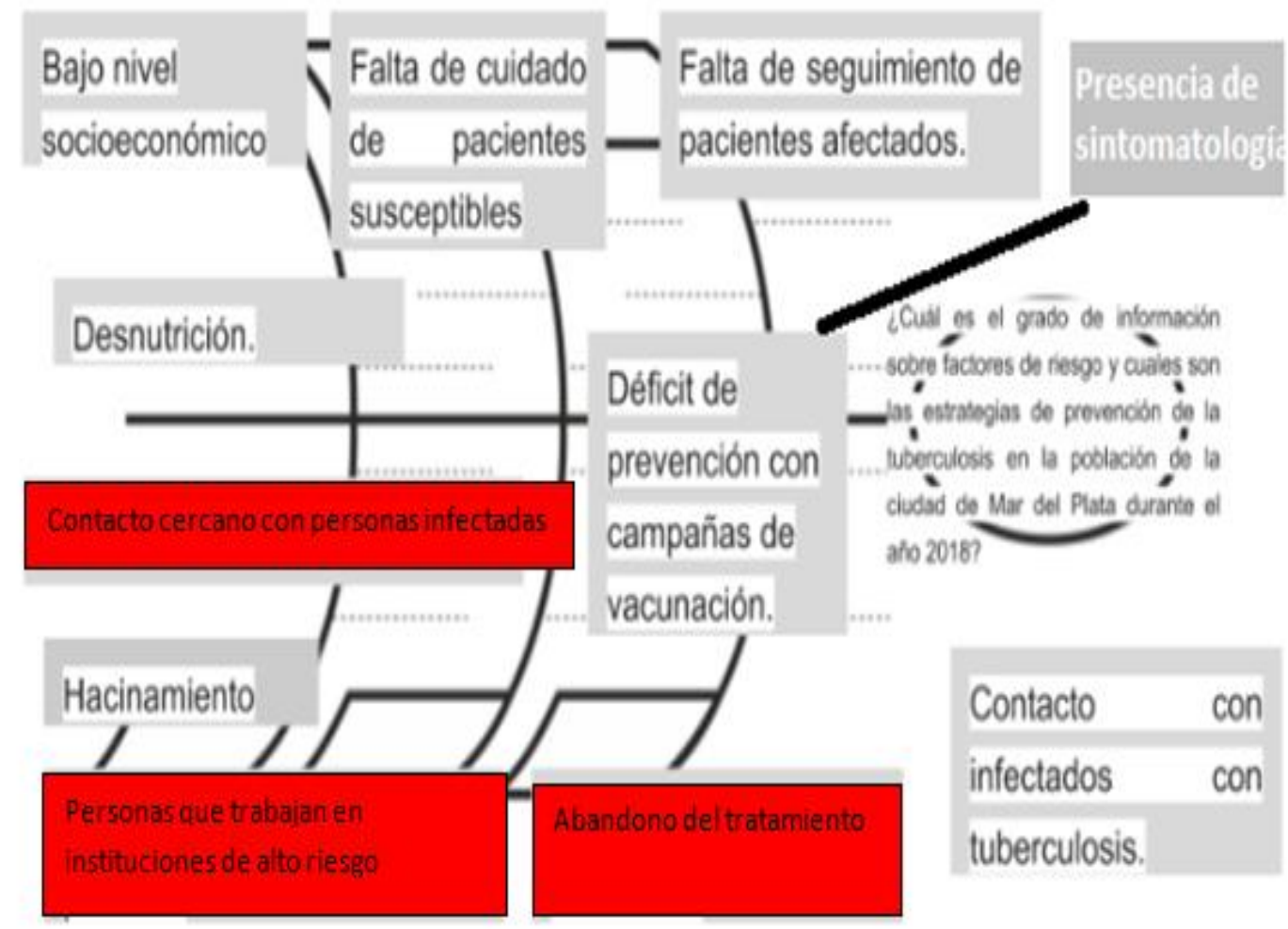

Fuente: Elaborado por alumnos de la cátedra de Metodología

${ }^{8}$ Kaoru Ishikawafue el creador de esta conocida técnica empleada por muchas disciplinas. 


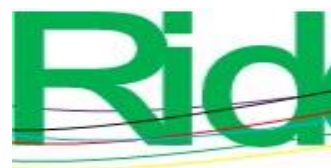

Revista Iberoamericana para la Investigación y el Desarrollo Educativo

ISSN $2007-7467$

En este caso se percibe el pasaje del conocimiento explícito altácito,y se observaun verdadero dinamismo en forma de bucle, y esto genera interrogantes (Nonaka y Takeuchi,2000, p.4) Al finalizar la tercera actividad virtual propuesta, se envía una encuesta con un formulario online para consultar aspectos que permitirán optimizar las actividades propuestas, cuyos resultados se visualizan a continuación, en la figura 10.

Figura 10. Percepción de alumnos del grado de dificultad segúnla fase realizada

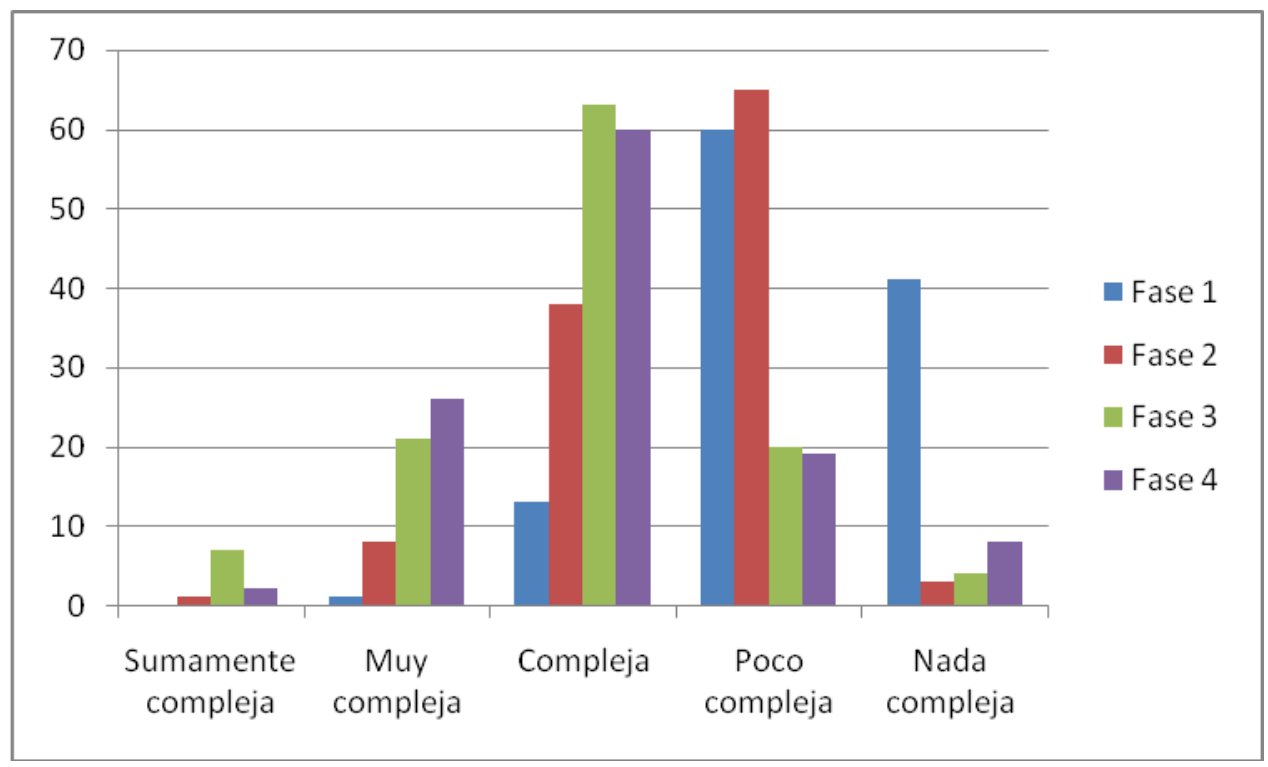

Fuente: Elaborado por alumnos de la cátedra de Metodología (2018)

La fase 3, correspondiente a la identificación de conceptos que podrían asociar con otra disciplina, la reconocen como compleja, al igual que la fase4; mientras que la fase 1 la reconocieron como poca compleja.

Cuando se indaga sobre en qué fase comienza la disciplinariedad a esfumarse, permitiendo una urdimbre entre las disciplinas, los alumnos manifiestan que desde la fase 3 aprecian este fenómeno. 


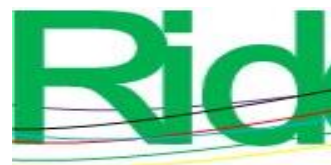

Revista Iberoamericana para la Investigación y el Desarrollo Educativo

ISSN $2007-7467$

Figura 11. Percepción de trabajo disciplinar/interdisciplinar según la fase desarrollada

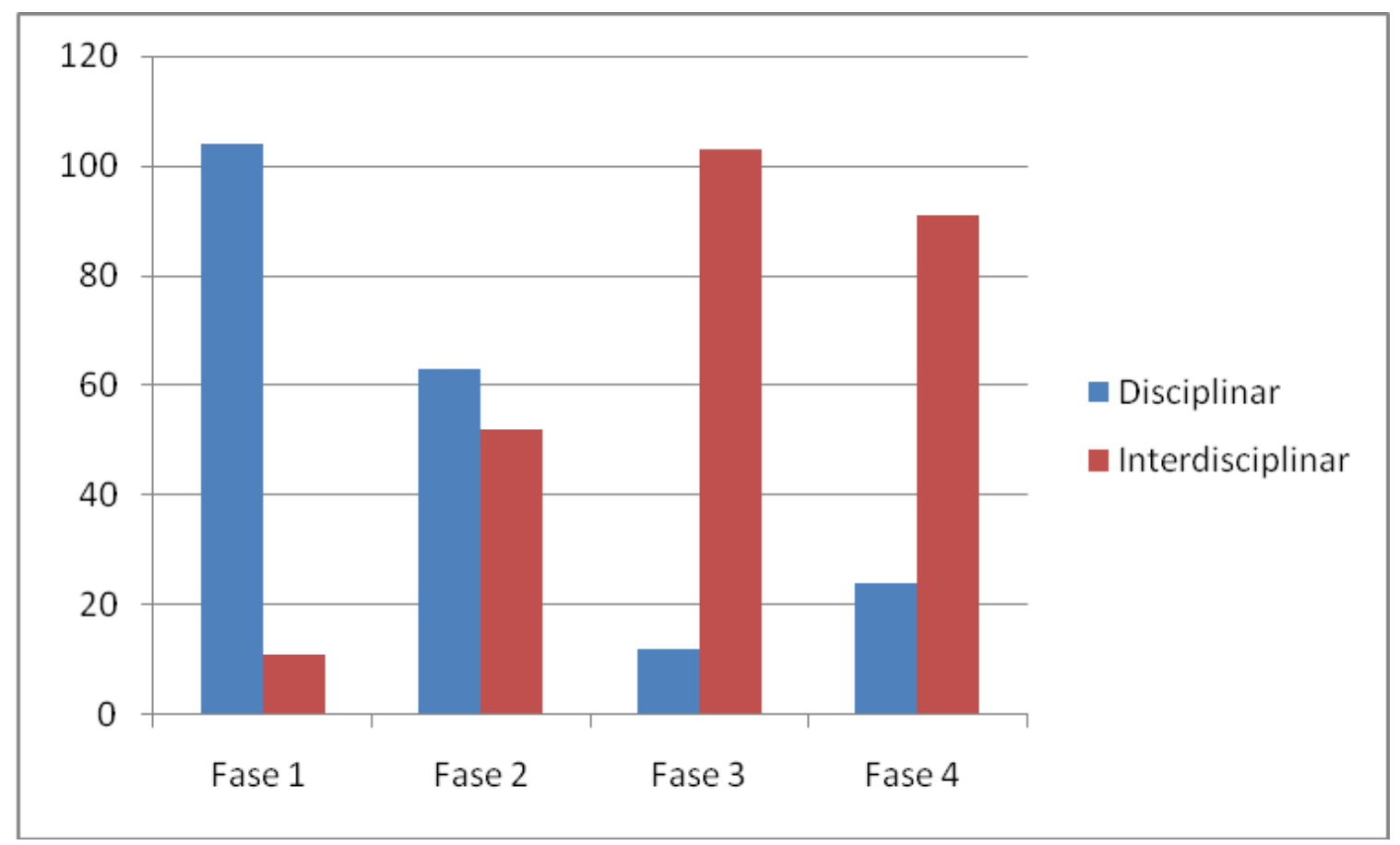

Fuente: Elaborado por alumnos de la cátedra de Metodología (2018)

Cuando se indago respecto a cuál es la opinión sobre las actividades desarrolladas, algunas de las respuestasobtenidas fueron: "El agradable intercambio que se realizó con compañeros con los cuales nunca había interactuado y el punto de vista que ofrecen otras carreras distintas a la mía. "Que sean tan importantes el resto de las disciplinas en la recuperación tratamiento de una enfermedad que yo consideraba de manejo exclusivo del área de la medicina". "Que dentro de una patología que he estudiado muchas veces surgieron conceptos nuevos, y que nunca hubiese relacionado con la tuberculosis”.

\section{Discusión}

En toda actividad formulada dentro de este estilo de trabajo es fundamental realizar una evaluación continua o de proceso, coincidiendo con Halcones yGonzález (2004, pp. 1114). Esto permite detectar dificultades que se representen los estudiantes. Y de esta forma el docente podrá dar indicaciones que faciliten realizar los ajustes para alcanzar las expectativas de logroplanteadasyasí "tomar las medidas necesarias". Entre las fortalezas que se identifican al implementar la experiencia se destaca que los alumnos logren atravesar las imaginarias puertas de las disciplinas para avanzar en elaboración de unproducto interdisciplinario, y el fortalecimiento del trabajo en grupo deforma 


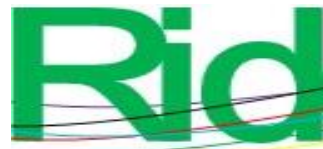

Revista Iberoamericana para la Investigación y el Desarrollo Educativo

ISSN $2007-7467$

colaborativa en un clima de respeto. Como limitación se detecta que el tiempo asignado fue escaso, ya que los estudiantes les hubiera gustado avanzar en una investigación con el problema planteado. Si bien en esta oportunidad se trabajó con cuatro carreras, sería interesante incrementar el número a seis, y modificar el diagrama diseñado.

\section{Conclusiones}

La fluidez con que se mueve el conocimiento científico actualmente requiere una permanente revisión de prácticas que favorezcan la enseñanza y aprendizaje de los diversos contenidos que se deben desarrollar en una cátedra universitaria. El elaborar un problema de investigación es uno de los pasos claves. Todo paciente debe ser atendido de forma integral y esto exige un entrenamiento en el trabajo interdisciplinario de los alumnos que cursan carreras en ciencias médicas.

\section{Agradecimientos}

En primer lugar, a Dios, quien me permite buscar caminos para mi crecimiento espiritual y profesional.

A mi familia, fuente de inspiración permanente.

Amish maestros por su generosidad y paciencia. 


\section{Referencias}

Angulo, R. (2017). Gestión del conocimiento y aprendizaje organizacional: una visión integral.InformesPsicológicos, $17(1)$ 53-70. doi:http://dx.doi.org/10.18566/infpsic.v17n1a03

Bartolomé, A. R. (2004). Blendedlearning. Conceptos básicos. Pixel-Bit: Revista de Medios y Educación, 23, 7-20.

Editorial"Preocupan casos de tuberculosis en Mar del Plata Es una enfermedad que volvió a emerger" [Editorial] (8 de enero de 2018) 0223,Recuperado de : https://www.0223.com.ar/nota/2018-1-8-14-10-0-preocupan-los-casos-detuberculosis-en-mar-del-plata-es-una-enfermedad-que-volvio-a-emerger

Esteban, P. G., Tosina, R. Y., Delgado, S. C. y Fustes, M. L. (2011). Buenas prácticas en el desarrollo de trabajo colaborativo en materias TIC aplicadas a la educación. Profesorado. Revista de currículum y formación de profesorado,15(1), 179-194.

González, F. S. (2005). Herramientas colaborativas para la enseñanza usando tecnologías web: weblogs, redes sociales, wikis, Web 2.0. Simposio llevado a cabo en la conferencia de la Universidad de León.

Halcones, M. Á. G. y González, N. P. (2004). La evaluación del proceso de enseñanzaaprendizaje. Fundamentos básicos. [Monografía]. Docencia e investigación, 14,4. Recuperado de http://hdl.handle.net/10578/7951.

Hernández, R., Fernández, C. y Baptista, P. (2010). Metodología de la investigación (3. ${ }^{\text {a }}$ ed.). México: McGraw-Hill.

López, J. I. (2011). Un giro copernicano en la enseñanza universitaria: formación por competencias Revista de educación, (356), 279-301. Recuperado de https://sede.educacion.gob.es/publiventa/un-giro-copernicano-en-la-ensenanzauniversitaria-formacion-por-competencias/investigacion-educativa/22922.

Lucero, M. M. (2003). Entre el trabajo colaborativo y el aprendizaje colaborativo. Revistaiberoamericana de Educación, 33(1), 1-21.

Minnaard, V. y Minnaard, C. (2017). Percepción sobre competencias que se fortalecen al implementar una Caza del Tesoro de Ciencia y Conocimiento Científico. Ponencia presentada en el VI Congreso Internacional de Competencias Laborales (Coincom). Cartagena de Indias. 


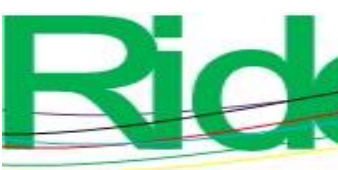

Revista Iberoamericana para la

Investigación y el Desarrollo Educativo

ISSN $2007-7467$

Minnaard, V. y Minnaard, C. (2018). Iniciando la mirada en Política Científica en la cátedra de Metodología de la Investigación. Ponencia presentada en el XXV Congreso Internacional de Aprendizaje. Atenas, del 21 al 23 de junio de 2018.

Nonaka, I., \& Takeuchi, H. (2000). La empresa creadora de conocimiento. Gestión del conocimiento, 1-9.

Posada, L. M. L. (2008). Interdisciplinariedad: una nueva forma de generación de conocimiento. Revista Mundo Económico y Empresarial, (6).

Organización de las Naciones Unidas [ONU]. (2019). La Agenda 2030 y los Objetivos de Desarrollo Sostenible. Una oportunidad para América Latina y el Caribe. Objetivos, metas e indicadores mundiales. Santiago, Chile: Organización de las Naciones Unidas. Recuperado de https://cepal.org/es/publicaciones/40155-laagenda-2030-objetivos-desarrollo-sostenible-oportunidad-america-latina-caribe.

Sánchez, M. (2005). Breve inventario de los modelos para la gestión del conocimiento en las organizaciones. ACIMED, 13(6) Recuperado de http://scielo.sld.cu/scielo.php?script=sci_arttext\&pid=S102494352005000600006\&lng=es\&tlng=es.

Tamayo, M. (2004). El proceso de la investigación científica. Ciudad de México, México: Editorial Limusa.

\section{Vivian Aurelia Minnaard}

Licenciada en Ciencias Biológicas, magister en Metodología de la Investigación Científica, doctora en Filosofía Especializada en Educación y postdoctoranda en Innovación, Cultura y Tecnología. Actualmente se desempeña como profesora titular de la materia Metodología de la Investigación en las Licenciatura en Nutrición, Fonoaudiología, Kinesiología y Medicina de la Universidad Fraternidad de Agrupaciones Santo Tomás de Aquino (UFasta). Y también es titular de la cátedra Metodología de la Investigación en el Profesorado de Geografía y Matemática del Instituto de Formación Docente No 19. Es miembro del comité científico de la revista Ingeniumde la Facultad de Ingeniería de la Universidad Nacional de Lomas de Zamora. Participa desde el 2009 en la red de profesores del Instituto Iberoamericano de la Enseñanza de las Ciencias y la Matemática (Iberciencia) 